\title{
Inaugural editorial: Communication
}

\author{
Richard D. Weisel, MD
}

With this issue, I assume the position of Editor of the Journal and this essay provides an outline of what we hope to accomplish in the next year.

I am thankful for the amazing achievements of my predecessors. I stand on the shoulders of giants. In this issue of the Journal is the Presidential Perspective of Dr Lawrence H. Cohn, immediate past Editor. The Journal is in a good place now. In the future, we hope to capitalize on the radical technological advances in our society to better connect with you our readers.

We live in amazing times and in the next decade you will see even more rapid progress in communication. Now you use multiple devices to connect. In a few years, these devices will merge and the information you want will be delivered directly to you. The Journal will attempt to provide the information you want in the way you want to receive it.

You said you wanted the Journal to focus on quality and excellence-and provide a forum for discussion of the issues facing cardiothoracic surgery. We hope to provide valuable material - in print and on your desktop, tablet, and smartphone. Surgeons are visual and the content will be enhanced with pictures and videos-interactive with commentaries and debates. A central picture will be selected for each paper, which will identify the contribution in all of our announcements.

At the heart of our efforts is the mission of the AATS: Promote Scholarship, Innovation, and Leadership in Thoracic and Cardiovascular Surgery. The new mission of the Journal is Advancing Excellence and Impact on the Specialty. All of the AATS publications will be dedicated to these missions and committed to excellence.

To accomplish these goals, the AATS publications will be integrated and coordinated to provide the best products possible to our readers. Over the next year, we will harmonize the publications and provide new communication platforms. We hope that you will enjoy the new face of our publications and that you will tell us what we need to do to improve our presentation. We propose 6 enhancements: a focus on excellence, shorter review times, more perspectives on the published work, more guidelines

\footnotetext{
From the Division of Cardiac Surgery, Toronto General Hospital, Toronto, Ontario, Canada.

Disclosures: Author has nothing to disclose with regard to commercial support.

Address for reprints: Richard D. Weisel, MD, Division of Cardiac Surgery, Toronto General Hospital, 200 Elizabeth St, EN 14-215, Toronto, Ontario, Canada M5G 2C4 (E-mail: rweisel@uhnresearch.ca).

J Thorac Cardiovasc Surg 2014;148:1147-8

$0022-5223 / \$ 36.00$

Copyright $(2014$ by The American Association for Thoracic Surgery http://dx.doi.org/10.1016/j.jtcvs.2014.08.037
}

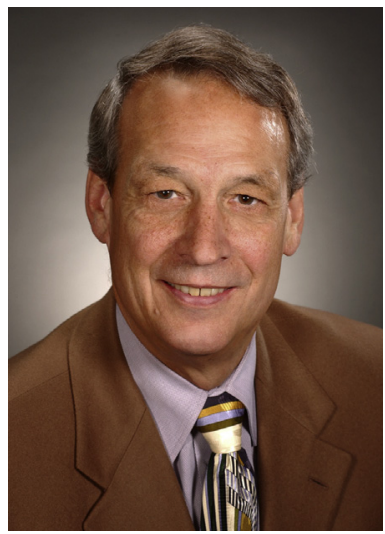

and editorials, enhanced coordination among the AATS publications, and enriched vehicles for communication.

1. Excellence. The Journal will publish high-quality papers that will have a substantial impact on our specialty. To ensure excellence and increase impact, we reviewed the publications in the Journal over the last 2 years and identified those with the largest number of citations, hits, and downloads and provided this information to the Associate Editors and reviewers. Not surprising, multicentered reports with long follow-up generated the most citations. We hope to refine this investigation to guide our reviewers to select the papers with the most impact for our specialty. We also plan to ensure that all accepted papers have conclusions supported by convincing statistics. Papers with advanced statistics will be reviewed by statistical reviewers under the direction of our Statistical Editor. The Journal will be dedicated to publishing high-quality papers.

2. Time for Review. We hope to reduce the review time and provide the first response to an author within 14 days after a paper is submitted. We hope to increase the efficiency in the editorial office and obtain a rapid response from our reviewers. We will expand the Editorial Board to include more reviewers who are able to provide high-quality assessments within this time frame.

3. Perspectives. Because only high-quality papers will be accepted for publication, we will provide our readers the reasons for selecting each paper and what impact we anticipate the information will have on the field. Authors will be asked to explain the importance of their observations for our readers and we will publish an editorial commentary with most papers. Additional editorials will provide an overview of important topics addressed by the papers in the Journal. We will also publish Expert Reviews and 
Commentaries that will indicate the importance and relevance of the published papers for the readers.

4. Guidelines and Editorials. Although the original manuscripts are the heart of the Journal, we will also ensure that we have additional popular content. AATS Guidelines will address issues important to cardiothoracic surgeons. We will also partner with other organizations to jointly publish international guidelines and consensus statements with commentaries from cardiothoracic surgeons. Comments on new information published by cardiothoracic surgeons in other journals will also be published to highlight important innovations. Most issues will also have opinion pieces and commentaries from our Editors, interest group leaders, and young surgeons.

5. Coordination among AATS Publications. For each area of interest, we will alert our readers to important information available in the other AATS publications. Papers felt to have important new information, but that may not have the exceptional impact required for the Journal, may be transferred for publication in the Seminars in Thoracic and Cardiovascular Surgery after approval by the authors and the Seminars Editors. The authors will be given the option of publication in the Seminars accompanied by editorial commentaries and, for AATS or WTSA papers, the meeting discussions. Each major section of the Journal will have links to important publications in the Seminars or
Operative Techniques in Thoracic and Cardiovascular Surgery as well as videos of the meeting presentations and roundtable discussions. Eventually, we hope to provide immediate linkage from the print version as well as from the online platforms.

6. Communication Vehicles. Our readers would like to have their content tailored to their interests and delivered in a coordinated fashion on the devices they use every day-computers, tablets, smartphones, Facebook, and Twitter. The AATS will work to deliver high-quality information in all of these formats. The Thoracic Surgery News has recently upgraded its Web site to provide a better platform for the latest news from the AATS, their journals, and other world-wide publications. We plan to enhance the content in the News with commentaries from surgical experts, coordinated with the other publications.

This issue will initiate some of these changes. Three papers about multiple arterial grafting are featured with an editorial overview by Drs Michael Halkos and Robert Guyton. Additional editorial Commentaries are included with many of the papers.

In the future, communication will be enhanced. We hope to ensure that the Journal provides high-quality information with expert commentaries in the formats preferred by our readers. 